\title{
Effect of Microwave Irradiation on Friedel-Crafts Diphenylmethylation of Arenes
}

\author{
Yutaka Okada*, Masahiro Yamabe \\ Department of Applied Chemistry, Ritsumeikan University, Shiga, Japan \\ Email: *ygvictor@sk.ritsumei.ac.jp
}

How to cite this paper: Okada, Y. and Yamabe, M. (2018) Effect of Microwave Irradiation on Friedel-Crafts Diphenylmethylation of Arenes. Green and Sustainable Chemistry, 8, 130-138.

https://doi.org/10.4236/gsc.2018.81009

Received: December 28, 2017

Accepted: February 24, 2018

Published: February 27, 2018

Copyright (๑) 2018 by authors and Scientific Research Publishing Inc. This work is licensed under the Creative Commons Attribution International License (CC BY 4.0).

http://creativecommons.org/licenses/by/4.0/

\begin{abstract}
The reaction between diphenylmethanols and substituted benzenes is useful to yield triarylmethane derivatives which are important skeletons in various functional materials and biologically relevant substances. The Reactions were carried out under microwave irradiation as environmentally-friendly method. In cyclohexane, the reaction was accelerated under microwave irradiation as compared to under conventional heating. Also, when more than 0.8 equivalents of iron(III) chloride were used, the acceleration was observed. Notably, when iron(III) chloride and arenes were combined, the temperature of the reaction solution rose to $40^{\circ} \mathrm{C}$. It is considered that a chemical species was formed upon coordination of iron(III) chloride to the diphenylmethanols or arenes.
\end{abstract}

\section{Keywords}

Microwave Irradiation Effect, Friedel-Crafts Reaction, Iron(III) Chloride

\section{Introduction}

Recently, environmental problems such as global warming caused by energy consumption have garnered concern [1] [2]. As such, it is necessary to develop efficiently and environmentally friendly reactions in synthetic organic chemistry. Towards that end, improvements in reaction yield and selectivity under microwave irradiation compared to conventional heating have been reported [3] [4].

Diarylmethane and triarylmethane derivatives are important skeletons in various functional materials and biologically relevant substances [5]. They are generally synthesized by the reaction between benzyl derivative 1 as an electrophile and arene 2 as a nucleophile (Scheme 1). With regard to the synthesis of compound 3, direct arylation via Friedel-Crafts using a Lewis acid catalyst has been 
<smiles>[R3]c1cccc(C([R])([R])[Y])c1</smiles>

1<smiles>[X]c1[R4]cccc1</smiles>

2<smiles>[R3][R]1cccc(C([R1])([R2])c2cc[R4](C)cc2)c1</smiles>

3

Scheme 1. The reaction between benzyl derivatives and arenes.

reported [6]. The Friedel-Crafts reaction is a typical carbon-carbon bond forming reaction used in synthetic organic chemistry. Mechanistically, the Lewis acid coordinates to the haloalkane to give an alkyl cation. Thereafter, the alkyl cation electrophilically attacks the arene to yield a product with a new carbon-carbon bond. Among Friedel-Crafts reactions, reactions with alcohols are environmentally friendly because the by-product is water.

In regard to viable catalysts for Friedel-Crafts reactions, various Lewis acids [7], Bronsted acids [8], and transition metal complexes [9] have been developed. However, such catalysts are often expensive, toxic, and air-sensitive. Therefore, reactions using iron as a Lewis acid catalyst have attracted attention, because iron is inexpensive and relatively environmental-friendly [10] [11].

In this study, a Friedel-Crafts diphenylmethylation reaction using iron(III) chloride as a catalyst was developed for the environmentally friendly synthesis of triarylmethane derivatives. The reactions were carried out under conventional heating and microwave irradiation, and a mechanism was proposed.

\section{Experimental}

\subsection{Instruments}

${ }^{1} \mathrm{H}$ and ${ }^{13} \mathrm{C}$ NMR were measured in chloroform- $\mathrm{d}$ at room temperature using a JEOL A-400 spectrometer.

GC data were acquired using a Shimadzu GC-14B with FID detector. Separation of the compounds was carried out using a Shimadzu HiCap-CBP10 (0.2 $\mathrm{mm}$ I.D. $\times 25 \mathrm{~m}, 0.25 \mu \mathrm{m}$ film thickness) capillary column, and the carrier gas was nitrogen. The GC oven was programmed at $240^{\circ} \mathrm{C}-270^{\circ} \mathrm{C}$.

\subsection{Substrate}

The substrates were purchased from Wako Chemicals, Ltd. The synthesized triarylmethanes are shown in Scheme 2.

\subsection{Friedel-Crafts Reaction}

Diphenylmethanols $(0.2 \mathrm{mmol})$ and substituted benzenes $(0.2 \mathrm{mmol})$ were dissolved in $20 \mathrm{~mL}$ of cyclohexane in the presence of iron(III) chloride $(0.2 \mathrm{mmol})$. The reaction flask was irradiated with $300 \mathrm{~W}$ microwaves. The reaction temperature increased to $35^{\circ} \mathrm{C}$. After the reaction, $30 \mathrm{~mL}$ of water was added to the flask, and the reaction mixture was extracted with $20 \mathrm{~mL}$ of ethyl acetate. The reaction yields were determined by GC. 


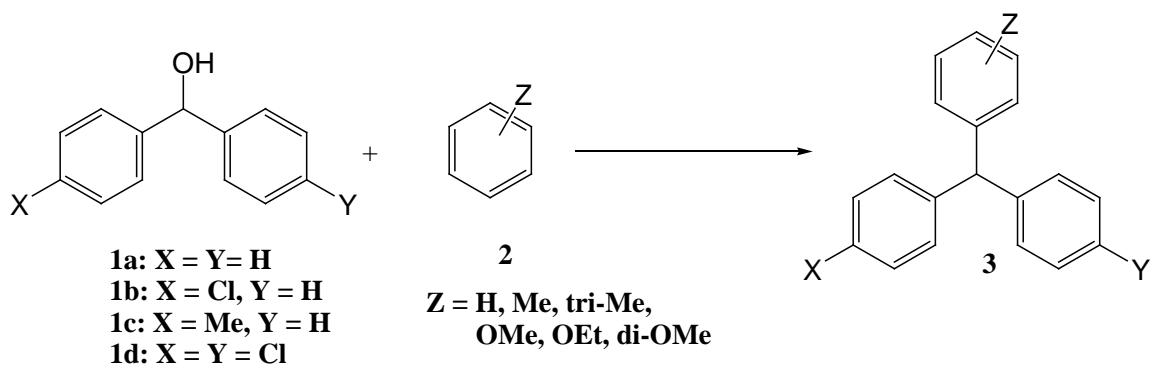

Scheme 2. The synthesized triarylmethanes.

For the reactions with diphenylmethanol and 4-chlorodiphenylmethanol, dichloromethane was used as the solvent. In this solution, the temperature reached the boiling point of the solvent.

The reaction temperatures under conventional heating conditions were $35^{\circ} \mathrm{C}$ in cyclohexane and reflux in dichloromethane.

The formed triarylmethanes were identified by ${ }^{1} \mathrm{H}$ and ${ }^{13} \mathrm{C}$ NMR. The yield was determined using GC.

\section{Results and Discussion}

\subsection{Reactions between Diphenylmethanols and Substituted Benzenes}

Reactions between diphenylmethanol and alkylbenzenes were carried out in dichloromethane (Table 1). In dichloromethane, no differences in the yields were observed under conventional heating or microwave irradiation, which was likely due to the absorbance of the microwaves by dichloromethane; as such, the substrate could not efficiently absorb the microwaves.

Therefore, the reactions were carried out in cyclohexane, which has a lower polarity than dichloromethane. However, no reaction occurred with the alkylbenzenes, so the reaction was attempted with several alkoxybenzenes. The yields of the reactions between diphenylmethanol and alkoxybenzenes are shown in Table 2.

With anisole and phenetol, the product yields under conventional heating were $48 \%$ and $50 \%$, respectively. Under the microwave conditions, the yields increased to $76 \%$ and $62 \%$, respectively. These results indicated the existence of a microwave irradiation effect.

On the other hand, with 1,2-dimethoxybenzene and 1,4-dimethoxybenzene, there was no difference in the yield, perhaps due to the lower reactivity of these alkoxybenzenes.

The results of the reactions with 4-chlorodiphenylmethanol are summarized in Table 3. The yields with 4-chlorodiphenylmethanol decreased compared to those with diphenylmethanol, likely because of the inefficient coordination with iron(III) chloride. However, the accelerating effect of the microwaves was observed with anisole and phenetol, similar to the case with diphenylmethanol. However, when using 1,2-dimethoxybenzene and 1,4-dimethoxybenzene, no 
Table 1. The yield of the reaction between diphenylmethanol 1a in dichloromethane $\mathrm{e}^{\mathrm{a}}$.

Substrate 2
2
3

a. $[1]=[2]=\left[\mathrm{FeCl}_{3}\right]=10 \mathrm{mM}, 0.2 \mathrm{mmol}$, b. Yield determined by GC.

Table 2. The yield of the reaction between diphenylmethanol 1a in cyclohexane $\mathrm{e}^{\mathrm{a}}$.

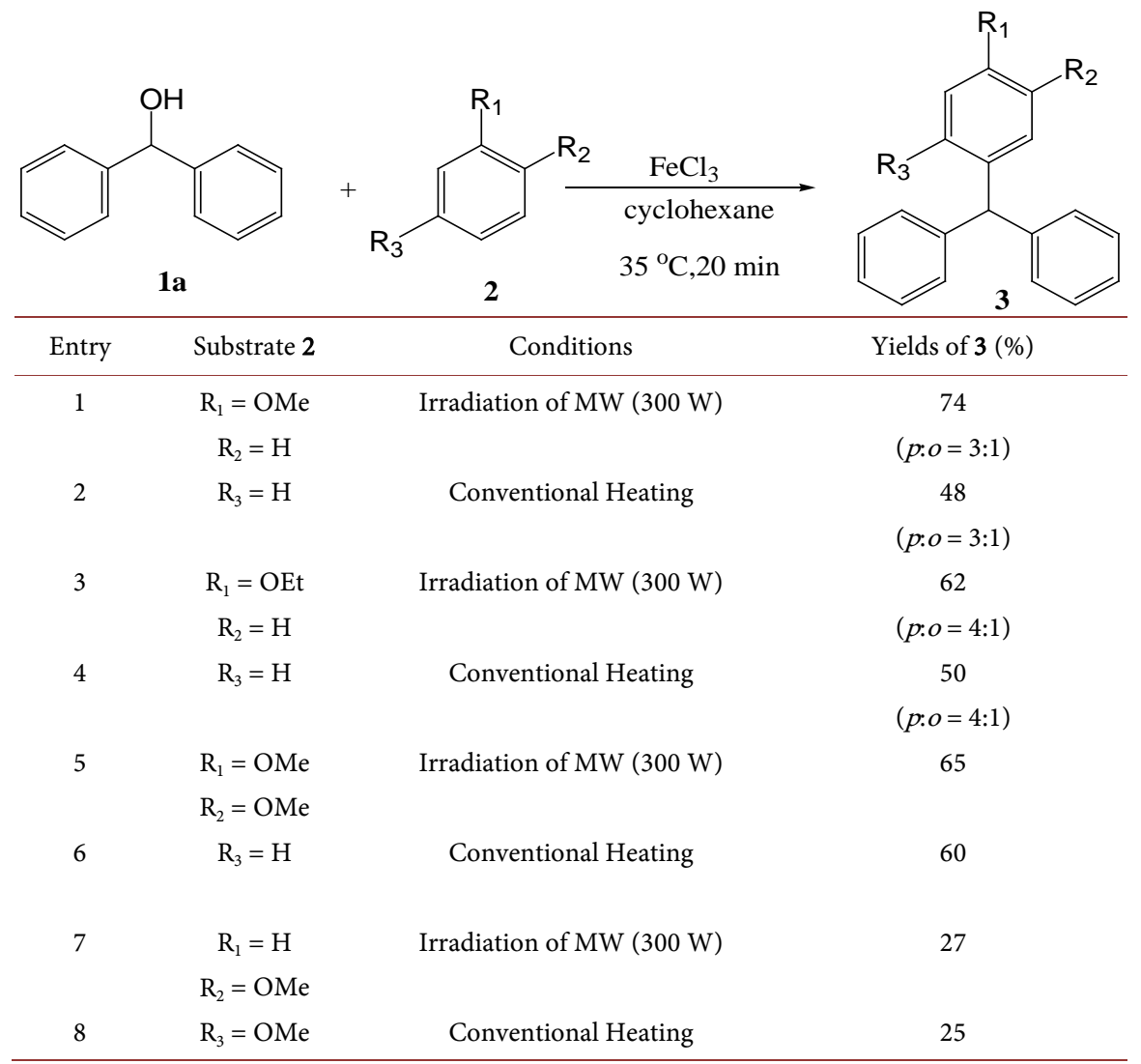

a. $[1]=[2]=\left[\mathrm{FeCl}_{3}\right]=10 \mathrm{mM}, 0.2 \mathrm{mmol}$, b. Yield determined by GC. 
Table 3. The yield of the reaction between 4-chlorodiphenylmethanol $1 \mathrm{~b}$ in cyclohexane ${ }^{\mathrm{a}}$.

$\mathrm{R}_{1}=\mathrm{OMe}$
3
3

a. $[1]=[2]=\left[\mathrm{FeCl}_{3}\right]=10 \mathrm{mM}, 0.2 \mathrm{mmol}$, b. Yield determined by GC.

difference in the yields was found under conventional heating or microwave conditions.

There was no difference in the yields in the reactions with 4-methlydiphenylmethanol under conventional heating or microwave conditions, owing to the high reactivity caused by the high electron donating effect of the methyl group (Table 4).

The microwave irradiation effect was observed in the reactions with 4,4'dichlorodipenylmethanol, as well as for the reactions with diphenylmethanol and 4-chloromethanol (Table 5). The results using 1,2-dimethoxybenzene and 1,4-dimethoxybenzene were also similar to those for diphenylmethanol and 4-chloromethanol.

\subsection{The Effect of Amount of Iron(III) Chloride on the Reaction between Diphenylmethanol and Anisole}

The amounts of iron(III) chloride were varied in the reaction between diphenylmethanol and anisole (Figure 1). With 0.2 - 0.6 equivalents of iron(III) chloride, no difference was found under conventional heating or microwave irradiation. However, in the presence of 0.8 equivalents of iron(III) chloride, the 
Table 4. The yield of the reaction between 4-methyldiphenylmethanol 1c in cyclohexane $\mathrm{e}^{\mathrm{a}}$.

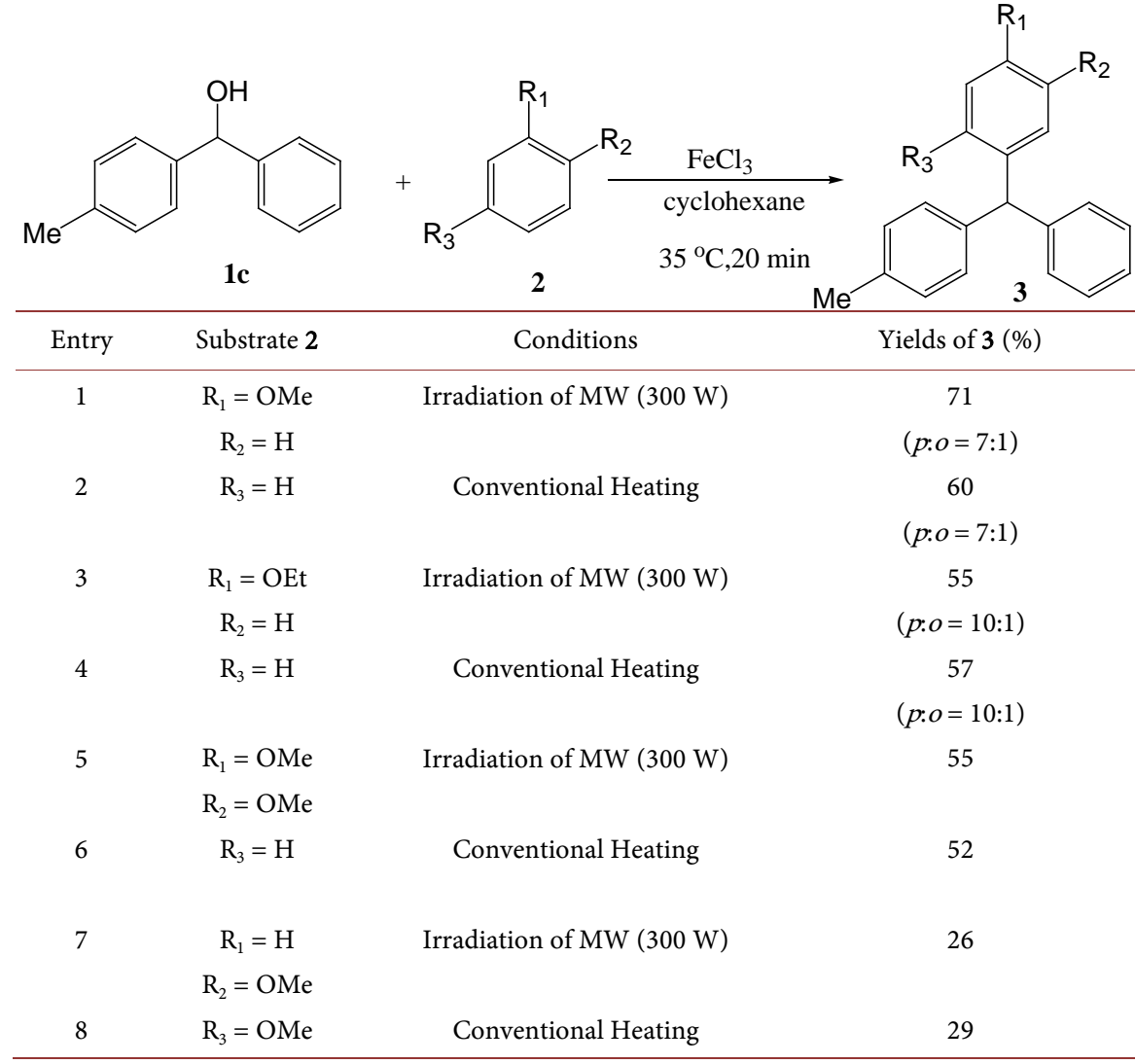

a. $[1]=[2]=\left[\mathrm{FeCl}_{3}\right]=10 \mathrm{mM}, 0.2 \mathrm{mmol}$, b. Yield determined by GC.

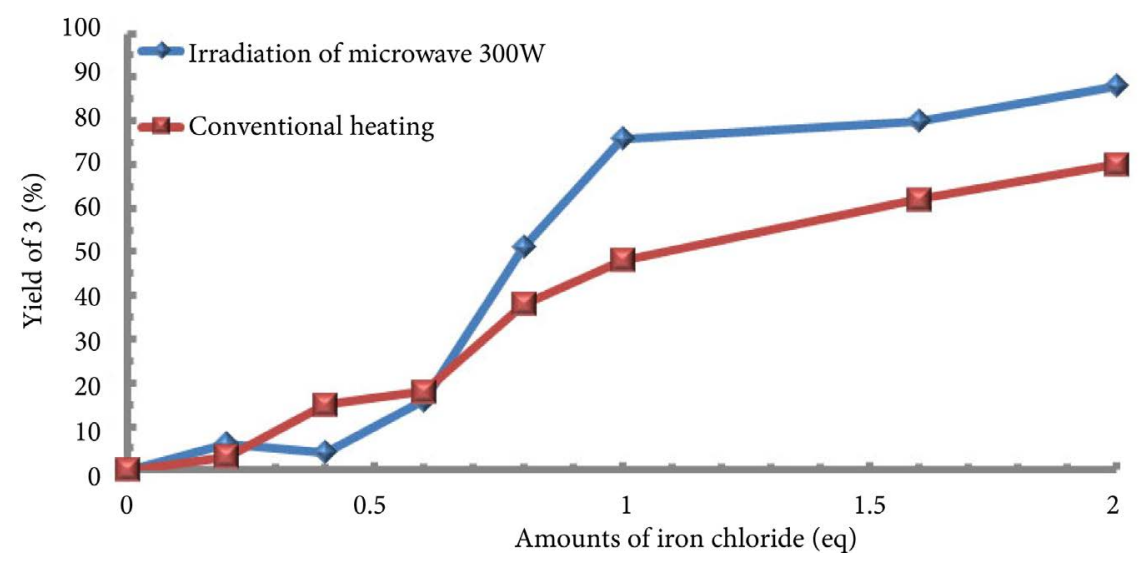

Figure 1. Amounts of iron chloride used in this reaction: comparison between Conventional heating and Irradiation of microwave.

accelerating effect of the microwave was observed. Based on these results, an equivalent amount of iron(III) chloride was necessary for the accelerating effect.

\subsection{Temperature of Reaction System}

The reaction temperature versus irradiation time plot is shown in Figure 2, where the amount of the substances was fifty times that in the reaction. For the 


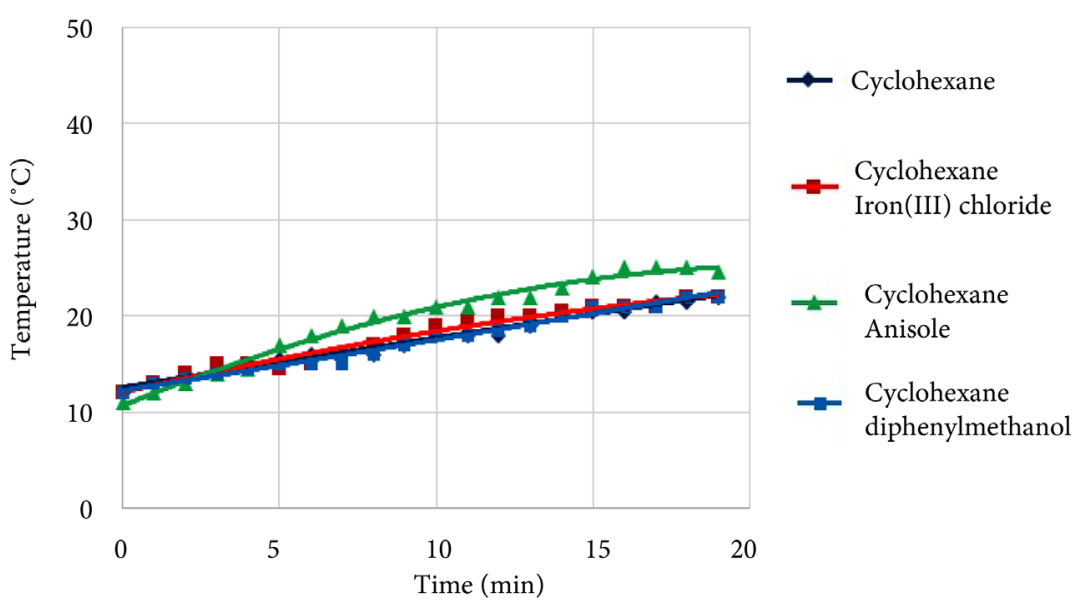

(a)

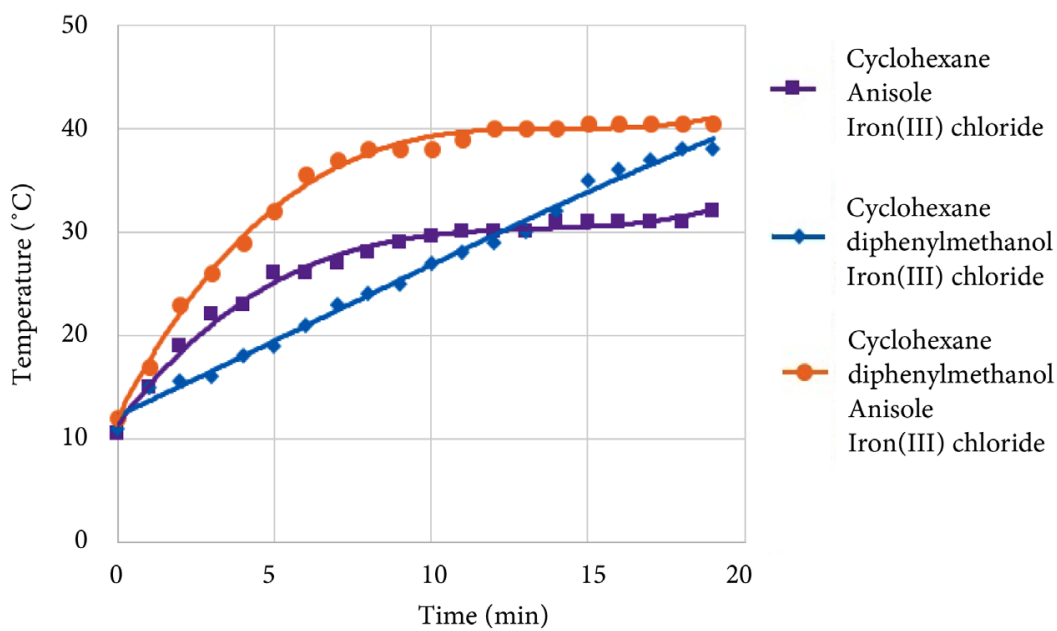

(b)

Figure 2. The temperature versus irradiation time.

substrates alone or iron(III) chloride alone, the reaction temperature was $24^{\circ} \mathrm{C}$; no temperature increase was observed (Figure 2(a)). However, when the substrates and iron(III) chloride were combined, the temperature increased to $40^{\circ} \mathrm{C}$ (Figure 2(b)), suggesting that the microwave energy was absorbed by the complex formed between the arenes and iron(III) chloride (Figure 3).

\section{Conclusion}

In cyclohexane, which is a low polarity solvent, microwave irradiation was found to accelerate the reaction between diphenylmethanol and alkoxybenzenes. However, when methylene chloride, which has a higher polarity, was used, no differences in the product yields were observed under conventional heating or microwave irradiation, perhaps due to the fact that methylene chloride absorbs the microwaves, and the substrates were not affected by the microwave energy. Furthermore, when more than 0.8 equivalents of iron(III) chloride were used, an accelerating effect was observed under microwave irradiation. Moreover, when 


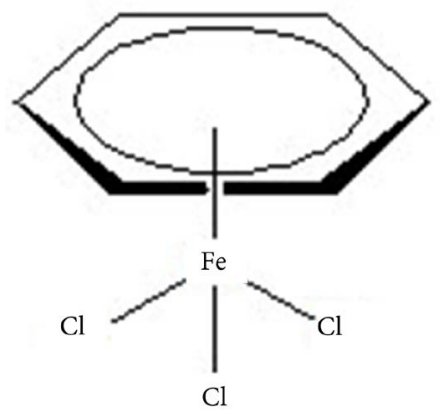

Figure 3. The complex between the arene and iron(III) chloride.

Table 5. The yield of the reaction between 4,4'-chlorodiphenylmethanol $1 \mathrm{~d}$ in cyclohexane $e^{\mathrm{a}}$.

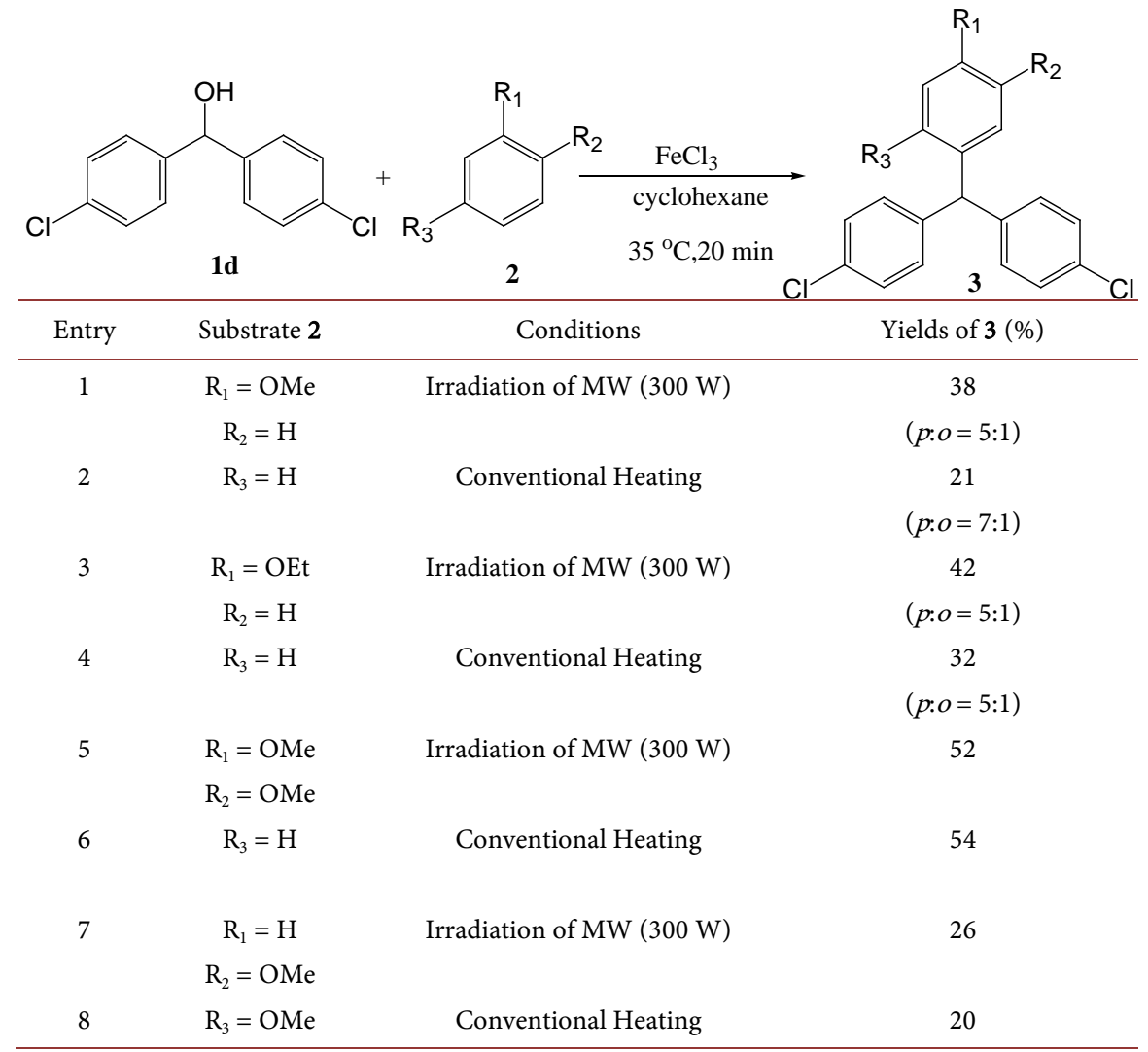

a. $[1]=[2]=\left[\mathrm{FeCl}_{3}\right]=10 \mathrm{mM}, 0.2 \mathrm{mmol}$, b. Yield determined by GC.

the arenes and iron(III) chloride were present, the reaction temperature increased to $40^{\circ} \mathrm{C}$. Therefore, iron(III) chloride plays an important role in accelerating the reaction. Namely, the chemical species formed upon coordination of iron(III) chloride to the arenes selectively absorbs the microwaves. Therefore, local heating around these chemical species would occur, and the acceleration effect would be affected by the increased temperature.

\section{References}

[1] Chen, P., Chen, S., Hsu. C. and Chen, C. (2016) Modeling the Global Relationships 
among Economic Growth, Energy Consumption and $\mathrm{CO}_{2}$ Emissions. Renewable \& Sustainable Energy Reviews, 65, 420-431. https://doi.org/10.1016/j.rser.2016.06.074

[2] Wang, C., Zhao, D., Tsutsumi, A. and You, S. (2017) Sustainable Energy Technologies for Energy Saving and Carbon Emission Reduction. Applied Energy, 194, 223-224. https://doi.org/10.1016/j.apenergy.2017.02.045

[3] Kappe, C.O. (2004) Controlled Microwave Heating in Modern Organic Synthesis. Angewandte Chemie International Edition, 43, 6250-6284. https://doi.org/10.1002/anie.200400655

[4] Hoz, A., Diaz-Ortiz, A. and Moreno, A. (2005) Microwave in Organic Synthesis; Thermal and Non-Thermal Microwave Effects. Chemical Society Reviews, 34, 164-178. https://doi.org/10.1039/B411438H

[5] Clarke, R., Leonessa, F., Welch. J.N. and Skaar, T.C. (2001) Cellular and Molecular Pharmacology of Antiestrogen Action and Resistance. Pharmacological reviews, 53, 25-72.

[6] Rueping, M., Nachtsheim, B.J. and Ieawsuwan, W. (2006) An Effective Bismuth-Catalyzed Benzylation of Arenes and Heteroarenes. Advanced synthesis \& catalysis, 348, 1033-1037. https://doi.org/10.1002/adsc.200606068

[7] Sun, H., Li, B., Chen, S., Li, J. and Hua, R. (2007) An Efficient Synthesis of Unsymmetrical Diarylmethanes from the Dehydration of Arenes with Benzyl Alcohols Using $\mathrm{InCl}_{3} \cdot 4 \mathrm{H}_{2} \mathrm{O} /$ acetylacetone Catalyst System. Tetrahedron, 63, 10185-10188. https://doi.org/10.1016/j.tet.2007.07.093

[8] Shirakawa, S. and Kobayashi, S. (2007) Surfactant-Type Bronsted Acid Catalyzed Dehydrative Nucleophilic Substitutions of Alcohols in Water. Organic Letters, 9, 311-314. https://doi.org/10.1021/ol062813j

[9] Mertins, K., Iovel, I., Kischel, J., Zapf, A. and Beller, A. (2005) Transition-Metal-Catalyzed Benzylation of Arenes and Heteroarenes. Angewandte Chemie International Edition, 44, 238-242. https://doi.org/10.1002/anie.200460666

[10] Bandini, M., Tragni, M. and Umani-Ronchi, A. (2009) Iron(III)-Catalyzed Intramolecular Friedel-Crafts Alkylation of Electron-Deficient Arenes with $\pi$-Activated Alcohols. Advanced Synthesis \& Catalysis, 351, 2521-2524. https://doi.org/10.1002/adsc.200900441

[11] Iovel, I., Mertins, K., Kischel, J., Zapf, A. and Beller, M. (2005) An Efficient and General Iron-Catalyzed Arylation of Benzyl Alcohols and Benzyl Carboxylates. Angewandte Chemie International Edition, 44, 3931. https://doi.org/10.1002/anie.200462522 